\title{
Ultrahigh bandwidth signal processing
}

\section{Oxenløwe, Leif Katsuo}

\section{Published in:}

Proceedings of Spie

Link to article, DOI:

10.1117/12.2235053

Publication date:

2016

\section{Document Version}

Peer reviewed version

Link back to DTU Orbit

\section{Citation (APA):}

Oxenløwe, L. K. (2016). Ultrahigh bandwidth signal processing. In Proceedings of Spie (Vol. 9894). [98940D] SPIE - International Society for Optical Engineering. Proceedings of SPIE - The International Society for Optical Engineering https://doi.org/10.1117/12.2235053

\section{General rights}

Copyright and moral rights for the publications made accessible in the public portal are retained by the authors and/or other copyright owners and it is a condition of accessing publications that users recognise and abide by the legal requirements associated with these rights.

- Users may download and print one copy of any publication from the public portal for the purpose of private study or research.

- You may not further distribute the material or use it for any profit-making activity or commercial gain

- You may freely distribute the URL identifying the publication in the public portal

If you believe that this document breaches copyright please contact us providing details, and we will remove access to the work immediately and investigate your claim. 


\title{
Ultrahigh bandwidth signal processing
}

Leif Katsuo Oxenløwe ${ }^{\text {a }}$

\author{
${ }^{a}$ DTU Fotonik, Technical University of Denmark, Ørsteds Plads 343, DK-2800 Kgs. Lyngby, \\ Denmark, Email address: 1kox@fotonik.dtu.dk
}

\begin{abstract}
Optical time lenses have proven to be very versatile for advanced optical signal processing. Based on a controlled interplay between dispersion and phase-modulation by e.g. four-wave mixing, the processing is phase-preserving, an hence useful for all types of data signals including coherent multi-level modulation formats. This has enabled processing of phase-modulated spectrally efficient data signals, such as orthogonal frequency division multiplexed (OFDM) signa In that case, a spectral telescope system was used, using two time lenses with different focal lengths (chirp rateq)s. yielding a spectral magnification of the OFDM signal. Utilising such telescopic arrangements, it has become possible perform a number of interesting functionalities, which will be described in the presentation. This includes conversion from OFDM to Nyquist WDM, compression of WDM channels to a single Nyquist channel and WDM regeneratio These operations require a broad bandwidth nonlinear platform, and novel photonic integrated nonlinear platforms like. aluminum gallium arsenide nano-waveguides used for 1.28 Tbaud optical signal processing will be described.
\end{abstract}

Keywords: Nonlinear optical signal processing, time lens, optical communications, nonlinear devices

\section{INTRODUCTION}

Optical time lenses are very versatile tools and allows for a large range of optical communication applications [1]. In [2 B. Kolner first described the equivalence between spatial and temporal optics, which has laid the foundation for tempo ], imaging and time lens optical signal processing. Time-to-frequency mapping is described in [3], and the use of $t_{\text {ral }}$, space-time duality in the context of spectral analysis is described in [4]. Timing jitter compensation is suggested in [5e and time-stretching for spectral fingerprinting is suggested in [6]. Distortion-free transmission is suggested in [ ], including a detailed derivation of the time-domain optical Fourier transformation (OFT) principle used for frequency- 7], time conversion. Arbitrary waveform generation e.g. for ultra-wideband communication [8] is also suggested. In [9] ${ }_{\text {to- }}$, description of various ultra-fast applications of time lenses are given, and in [10], the first demonstration of time lens a based on a silicon chip is presented. In [11], a good overview of recent ultrahigh-speed optical signal processing applications using time lenses is given. For optical signal processing of data signals, using four-wave mixing convenient, as it yields a very high phase modulation, i.e. a time lens effect. Figure 1 shows a schematic of the principl is

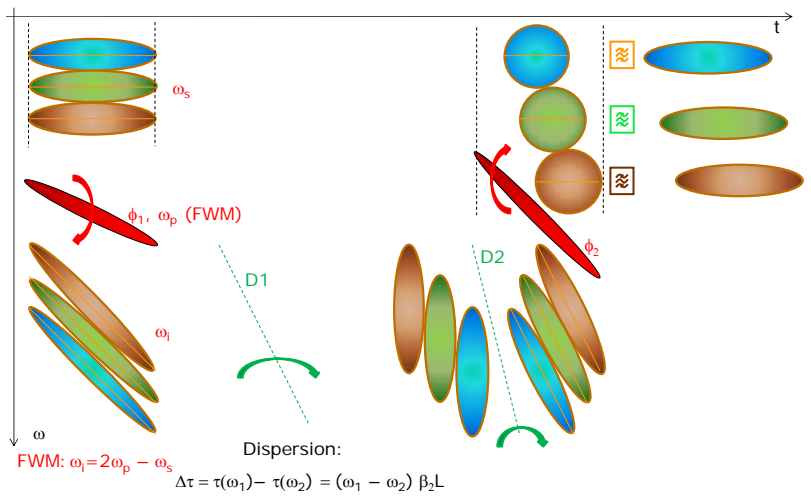

Figure 1. Spectrographic description of time lens based WDM grid manipulation utilizing a spectral telescopic arrangement with two time lenses (here, two four-wave mixing units) and dispersion units. The steps include parallel-to-serial conversion in a first time lens followed by serial-toparallel conversion in a second time lens. The chirp rate ratio between the two time lenses (or equivalently the matched accumulated dispersion $\mathrm{D}=\beta_{2} \mathrm{~L}$ ) determines the spectral magnification factor, $M=D_{1} / D_{2}$.

Spectral mapping using FWM follows the simple formula for the generated idler frequency: $\omega_{\mathrm{i}}=2 \omega_{\mathrm{p}}-\omega_{\mathrm{s}}$. Thus using a chirped pump (at frequency $\omega_{\mathrm{p}}$ ), i.e. a tilted waveform in the spectrographic representation in Fig. 1, will map signal frequencies $\left(\omega_{\mathrm{s}}\right)$ to idler frequencies $\left(\omega_{\mathrm{i}}\right)$, in a pulse twice as chirped as the pump. The generated frequencies will be mapped linearly by dispersion as $\Delta \tau=\Delta \omega \mathrm{D}$. Using these simple representations, it is easy to see how optical signals may be manipulated. Fig. 1 shows spectral magnification to twice the frequency separation. 


\section{APPLICATIONS}

Figure 2 shows a number of advanced applications using time lenses, with a focus on how these manipulations relate to legacy WDM transceivers.

a)

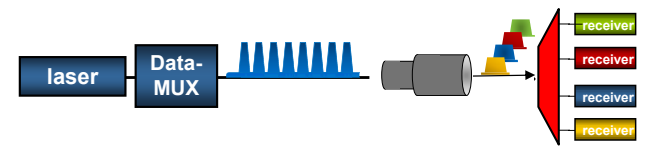

b)

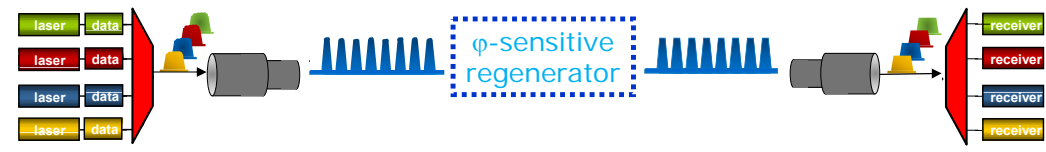

c)

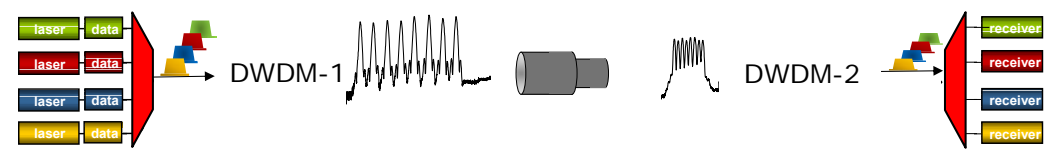

d)
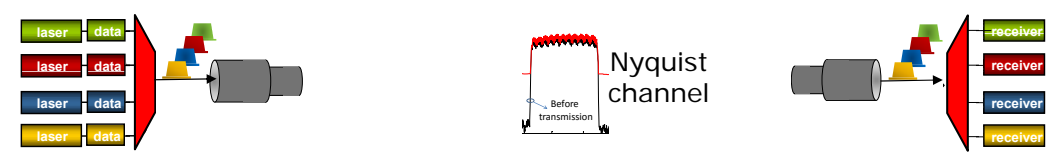

e)
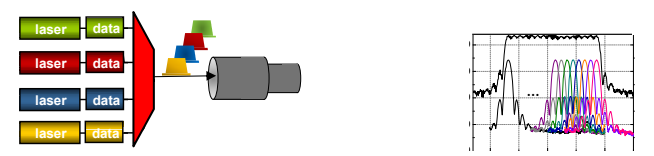

OFDM

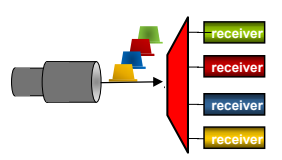

f)
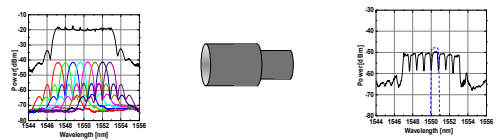

N-WDM

Figure 2. Overview of some essential demonstrated time lens functionalities and their relation to legacy WDM transmitters and receivers. a) Serial-to-parallel conversion [12] enabling OTDM reception using a passive WDM receiver. b) parallel-toserial conversion [13] with potential phase-sensitive regeneration followed by serial-to-parallel conversion [14] allowing for scalable WDM regeneration. c) WDM grid manipulation [15] enable flexible grid operation for e.g. increasing or decreasing

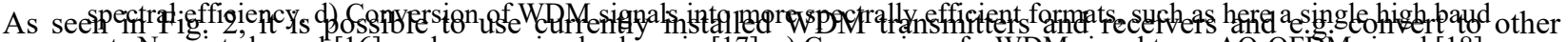

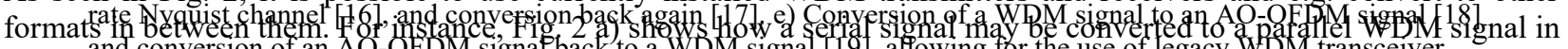

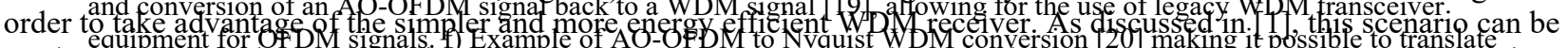

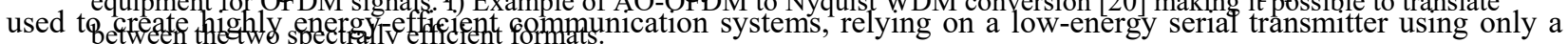
single laser source, and adapting the signal to a WDM receiver using a single time lens unit. The main idea behind this approach is to replace several power-hungry parallel devices with a single ultra-broadband device. In Fig. 2 b), a principle for WDM regeneration is presented. Again, the idea is to use a single broadband regenerator as opposed to individual regenerators for each WDM channel. The key to do this, is to first convert the WDM signal to a single serial channel (parallel-to-serial conversion) in a time-lens unit. As the optical signal processing schemes suggested for optical regeneration are mostly based on ultra-fast optical effects, it is straightforward to perform regeneration on a single ultrafast serial channel, but very challenging to treat several parallel WDM channels in the same unit. After regeneration the serial signal may be converted back to a WDM signal again and re-transmitted before being received in a WDM receiver [14]. Converting from parallel to serial and back again also implies the possibility of converting with different chirp 
rates. This will e.g. bring the WDM signal back to a different channel grid [15], i.e. frequency separation, Fig. 1 and 2 c). In figures $1 \& 2$, examples of spectral compression are shown, but it may equally be for spectral magnification, making it truly flexi-grid. Fig. 2 d) and e) show examples of taking a standard WDM signal and converting it to very spectrally efficient data formats. In Fig. 2 d), the WDM signal is converted to a single Nyquist channel (Nyquist OTDM) [16], i.e. where there are no guardbands within the spectral extent of the channel and orthogonal sinc-pulses in the time domain, yielding a pure binary spectral efficiency of 1. In [17], a 1.28 Tbaud Nyquist channel is created and a time lens based receiver is used to separate the individual channels again. In Fig. 2 e), the WDM signal is converted to an orthogonal frequency division multiplexed (OFDM) signal, with sinc-spectra and rectangular pulses [18] and subsequently back to a WDM signal again [19]. The latter will also have a potential for power reduction, as an all-optical (AO) OFDM receiver usually requires as many active gates as there are OFDM channels. These types of conversions may be very useful if one needs to upgrade ones WDM legacy installed links to higher spectral efficiency. Finally Fig. $2 \mathrm{f}$ ) addresses the fact that there are two main approaches being considered for deployment of spectrally efficient data signals, OFDM and Nyquist WDM. If both of these are installed, using a time lens unit will make it possible to directly convert between the two formats, ensuring full transparency in the optical domain [20]. Most time lens implementations have been based on FWM in highly nonlinear fibre (HNLF), giving a high conversion efficiency. Using photonic integrated nonlinear devices such as silicon nano-waveguides have been suggested and demonstrated [10,21], with the advantage of offering ultra-high bandwidth, however with low conversion efficiency. Recently, an AlGaAs-on-insulator nano-waveguide was demonstrated with high conversion efficiency and broad bandwidth [22] capable of processing a 1.28 Tbaud data signal.

\section{SUMMARY}

In this paper, an overview of advanced optical signal processing schemes based on optical time lenses have been presented. In particular, a focus has been given to the prospects of using legacy WDM transceivers in combination with time lens units to upgrade to more spectrally efficient data formats, more power efficient systems, or to perform WDM regeneration or WDM flex-grid operations. Time lenses offer many possibilities for advanced optical signal processing, and as more efficient nonlinear platforms are being developed, such as AlGaAs nano-waveguides, more practical implementations of time lens telescopic units become promising for future developments.

The author would like to acknowledge: DNRF CoE SPOC (DNRF123), DFF Adv.Gr. NANO-SPECs for funding, Dr.s Pengyu Guan, Hao Hu, Michael Galili, Mr. Mads Lillieholm, High-Speed Optical Communications grp., DTU Fotonik.

\section{REFERENCES}

[1] L.K.Oxenløwe et al, Ch. 8, Eds. B.J. Eggleton, S. Wabnitz, Springer, DOI 10.1007/978-3-319-14992-9 (2015)

[2] B. H. Kolner, J. Quantum Electro., 30 (8), (1994), p. 1951

[3] J. Azaña, Opt. Commun., 217 (1), (2003) p. 205

[4] J. Azaña et al, J. Quantum Electron., 36 (5), (2000) p. 517

[5] L. F. Mollenauer et al, Proc. CLEO 2002, paper CPDB1

[6] Y. Han et al, J. Lightwave Technol. 21, (2003), p. 3085

[7] M. Nakazawa et al, Photon.Technol. Lett., 16 (4), (2004), p. 1059

[8] I. S. Lin et al, IEEE Microwave and Wireless Compon. Lett. 15, (2005), p. 226

[9] J. v. Howe et al, J. Lightwave Technol., 24(7), (2006), p. 2649

[10] R. Salem et al, Optics Letters, 33 (10), (2008), p. 1047

[11] R. Salem, et al, Advances in Optics and Photonics, 5 (3), (2013), p. 274

[12] H.C.H. Mulvad et al, Opt. Express, 19 (26), (2011), p. 825

[13] H. C. H. Mulvad et al, Proc. ECOC 2011, paper Mo.1.A.5, 2011

[14]P. Guan et al, Proc. ECOC2015, paper We.3.6.4.

[15]E. Palushani et al, Proc. OECC 2013, Kyoto, Japan, July 2013. Paper ThO2-1

[16]P. Guan et al, Proc. ECOC 2014, DOI: 10.1109/ECOC.2014.6964033

[17] H. Hu, et al, CLEO Techn. Digest. Optical Society of America, 2013. Postdeadline paper CTh5D.5

[18]P. Guan et al, patent: IPC No.: H04J 14/ 00 A I. Patent No.: EP2916472

[19] E. Palushani et al, Optics Express 22 (1), (2014), p. 136

[20] P. Guan et al, Journal of Lightwave Technology, Vol. 34, No. 2, (2016), p. 626-632

[21] H. C. Hansen Mulvad et al, Proc. ECOC 2011, Postdeadline paper Th.13.A.2

[22] M. Pu et al, Proc. OFC 2015, Postdeadline paper Th5A.3 